* Doutor em Direito pela Pontifícia Universidade Católica de São Paulo (PUC-SP). Mestre em Direito Agrário pela Universidade Federal de Goiás (UFG). Especialista em Filosofia do Direito pela Pontifícia Universidade Católica de Minas Gerais (PUC-Minas). Graduado em Direito pela Universidade da Amazônia (UNAMA). Professor na Universidade Federal do Espírito Santo (UFES). Professor na Universidade Vila Velha (UVV). Coordenador do Grupo de Pesquisa "O Direito Civil na Pós Modernidade Jurídica”. Advogado. Email: lab1971@ gmail.com.

** Pós-graduanda (lato sensu) em Direito Público pela Pontifícia Universidade Católica de Minas Gerais (PUC-Minas). Graduada em Direito pela Universidade Federal do Espírito Santo (UFES). Participante do Grupo de Pesquisa "O Direito Civil na Pós Modernidade Jurídica”. Advogada. Email: brigidapassamani@hotmail.com.

\section{USUCAPĨ̃o EXTRAJUdICIAL: O \\ Procedimento PaRa ALÉM da \\ DesJudicialização}

\author{
Extrajudicial Adverse Possession \\ [Usucaption]: the Process for GoING \\ BEYOND THE REDUCTION OF JUDICIAL \\ INVOLVEMENT
}

Lucas Abreu Barroso* Brígida Roldi Passamani***

Como citar: BARROSO, Lucas Abreu; PASSAMANI, Brígida Roldi. Usucapião extrajudicial: o procedimento para além da desjudicialização. Scientia Iuris, Londrina, v. 21, n. 1, p.189-211, mar. 2017. DOI: $10.5433 / 2178-8189.2017 \mathrm{v} 21 \mathrm{n} 1 \mathrm{p} 199$. ISSN: 2178-8189.

Resumo: Este artigo enseja traçar linhas iniciais sobre o procedimento de usucapião a ser realizado pela via extrajudicial. Mas propõe-se também a uma investigação acerca deste novel instituto a partir de uma perspectiva crítica de direito material. Acaba, por fim, revelando que um de seus requisitos impede uma ampla e proveitosa utilização da inovação surgida no bojo do Código de Processo Civil de 2015.

Palavras-chaves: Direito civil. Posse. Função social. Usucapião extrajudicial. Código de 
Processo Civil de 2015.

Abstract: This study analyzes adverse possession, which is also known as usucaption or in Portuguese - usucapião. Nonetheless, the concrete realization of its procedure can be by extrajudicial or out-of-court means. Furthermore, this research investigates this novel institution from a depth of critical understanding of substantive law. In conclusion, this paper reveals a fundamental requirement that prevents its extensive and effective use, which became relevant with the introduction of the Brazilian Civil Procedure Code of 2015.

Keywords: Civil law. Possession. Social duty. Extrajudicial adverse possession [usucaption]. Brazilian Code of Civil Procedure of 2015. 


\section{INTRODUÇÃO}

O estudo que principia cinge-se à linha crítico-metodológica enquanto substrato de norteamento. Neste contexto, alicerça suas bases no pensamento jurídico crítico, particularmente no que cerca uma construção problematizada do direito. Assim, quanto ao seu desenvolvimento, busca trabalhar pela vertente jurídico-sociológica, haja vista a permanente necessidade de confrontação do conhecimento jurídico com a complexidade da realidade social. A partir desta opção, analisa o recorte temático por meio de raciocínio indutivo nos meandros de investigação de tipo jurídico-propositiva, eis que "[...] destina-se ao questionamento de uma norma, de um conceito ou de uma instituição jurídica, com o objetivo de propor mudanças ou reformas legislativas concretas" (GUSTIN; DIAS, 2013, p. 29).

O percurso histórico da aquisição imobiliária e das titularidades no Brasil vem marcado pela perspectiva monopolista do direito de propriedade, individualista e acentuadamente especulativo, o qual convergiu para o problema da concentração fundiária. Diante deste cenário, o processo de ocupação urbana e rural ocorreu de maneira irregular e iníqua, invocando pelos desafios estabelecidos na Constituição de 1988 , sobretudo nos arts. $1^{\circ}$, II, III e IV; $5^{\circ}$, XXIII; $6^{\circ}$, caput; 170 , III; 182, § 2 $2^{\circ}$, e 186.

O paradigma civilístico da modernidade ainda é amplamente percebido no cotidiano social por meio de uma lógica de distribuição de espaços na cidade e no campo que pouco assimila a estrutura real da sociedade brasileira, perpetuando o anseio pela acumulação fundiária, sem que seja efetivamente direcionada econômica e socialmente a 
utilização das glebas urbanas e rurais.

Com base neste englobar fático-jurídico, busca-se demonstrar como a posse em sua realização prática desempenha papel fundamental nas relações sociais, traduzindo-se como verdadeiro substrato do dinamismo social, exprimindo, inexorável e inerentemente, latente função social em sua simples existência, ao consubstanciar a expressão máxima do atuar humano na realização de suas necessidades, ao passo, e em contraste, do que pode ser observado quando a propriedade se encontra no cerne da proteção jurídica.

Nesta seara importa que se tenha em mente a evolução do instituto da usucapião no ordenamento jurídico constitucional e infraconstitucional brasileiro, como verdadeira exceção de direito material (TORRES, 2008, p. 424), no intuito de colher os primeiros avanços para ascensão da posse qualificada e visando consolidar o entendimento acima esboçado, referente à sobreposição da situação possessória à titularidade dominial, em razão de sua função social.

Traçados estes pontos iniciais, dirige-se a abordagem do texto à suposta facilitação proporcionada pelo novel diploma processual civil vigente desde março de 2016 acerca da possibilidade de que o procedimento de usucapião seja realizado extrajudicialmente em certa e específica hipótese normativa, sem necessidade da atividade jurisdicional, conforme art. 1.071.

Mas frise-se desde logo que não se trata de uma nova modalidade de usucapião. Pelo designativo usucapião extrajudicial, como vem sendo doutrinariamente anunciado, quer-se referir a um procedimento de reconhecimento do domínio alternativo ao processo judicial (OLGADO, 2015, p. 10).

O procedimento extrajudicial de usucapião seria aplicável a 
qualquer das modalidades de usucapião (TARTUCE, 2015, p. 327), que passariam a prescindir da obrigatoriedade da apreciação judicial, embora não a excluam (GAMA, 2016, p. 1). Entretanto, questiona-se: teria sido alcançada a mens legislatoris em face das exigências contidas nos incisos e parágrafos do correspondente dispositivo legal?

\section{A FUNÇÃO SOCIAL DA POSSE}

À primeira vista, o permissivo legal em análise demonstra-se, para além do conteúdo processual, como aprimoramento e desmistificação do acesso à propriedade, haja vista a simplificação do seu procedimento aquisitivo, evidenciando, ainda, a tendência de despatrimonialização do direito civil.

Não obstante, cumpre lembrar que a posse é entendida pela legislação brasileira como o exercício fático de quaisquer dos poderes inerentes à propriedade, nos termos do art. 1.196 do Código Civil.

Portanto, a partir da leitura deste dispositivo é possível notar a intencional subordinação da situação possessória ao direito de propriedade, categorizando-a como situação de fato, ainda que juridicamente relevante, como no caso das ações possessórias e da usucapião.

Todavia, faz-se necessário concretizar, com fulcro nos princípios constitucionais antes mencionados, a autonomia da posse, cuja força normativa comunga da mesma efetividade daquela da propriedade, uma vez ungida pela função social proativamente exercida, a fim lograr proteção jurídica à altura de sua relevância social.

Certos institutos jurídicos, como a usucapião, atuam no sentido de consolidar esta construção doutrinária. Sendo assim, facilitar a sua efetivação repercute mais adiante que a observação quanto ao 
procedimento processual em si mesmo considerado.

É inegável que a posse se apresenta como um forte percussor e realizador de objetivos sociais e humanos (MARQUESI, 2001, p. 119). O reclamo por seu definitivo reposicionamento no campo do direito é, pois, inadiável.

De igual forma, o Código Civil, o Estatuto da Cidade e o Estatuto da Terra fornecem elementos para qualificar a relação fática entre sujeito e coisa, de modo a legitimar o emprego da expressão "função social da posse".

Vale aqui uma transcrição doutrinária mais alongada em busca de uma mais adequada compreensão do assunto:

A função social da posse situa-se em plano distinto, pois, preliminarmente, a função social é mais evidente na posse e muito menos evidente na propriedade, que mesmo sem uso, pode se manter como tal. A função social da propriedade corresponde a limitações fixadas no interesse público e tem por finalidade instituir um conceito dinâmico de propriedade em substituição ao conceito estático, representando uma projeção da relação anti-individualista. $O$ fundamento da função social da propriedade é eliminar da propriedade privada o que há de eliminável. $\mathrm{O}$ fundamento da função social da posse revela o imprescindível, uma expressão natural de necessidade. (FACHIN, 1988, p. 13). [...] Enquanto vinculada à propriedade, a posse é um fato com algum valor jurídico, mas, como conceito autônomo, a posse pode ser concebida como um direito (FACHIN, 1988, p. 19).

Portanto, afere-se que a posse assume feições que não se reduzem a meros reflexos do direito de propriedade ou de outros direitos reais, que não pretendem ser aprioristicamente a encarnação da riqueza e 
muito menos a manifestação de um poder resultante da soberania privada. Trata-se, acima de tudo, de um direito voltado à necessidade humana.

É neste sentido que se trava o discurso diante do instituto da usucapião extrajudicial, como nada mais que o reconhecimento da autonomia possessória diante do confronto entre posse qualificada e propriedade desfuncionalizada, dispensando o exercício jurisdicional para o reconhecimento do direito à usucapião, afastando a artificialidade da posse meramente civil e "fantasmagórica" (BECKER; SANTOS, 2002, p. 120).

Contudo, a cautela exige que se esteja atento às variadas nuances da usucapião extrajudicial, não deixando que o otimismo ofusque mesmo os olhares mais atentos quanto a esta novidade procedimental.

Este texto não deixará de enveredar pelas críticas necessárias aos requisitos da usucapião extrajudicial tal como previstos no Código de Processo Civil, em especial àquele que desde logo acabou por desvirtuar o substrato e a aplicabilidade deste instituto jurídico já em seu nascedouro.

\section{A PROPRIEDADE DESFUNCIONALIZADA E A POSSE QUALIFICADA}

Há tempos a propriedade tem sido foco de conflitos e de disputas de índole socioeconômica e em todos esses momentos demostrou-se insuficiente a titularidade dominial para recompor as desestabilizadas relações jurídico-sociais entre particulares, e entre estes e o Estado (CASTRO, 2011).

$\mathrm{Na}$ história ocidental contemporânea a propriedade assumiu uma feição muito própria, ora como símbolo do poder econômico, ora como bandeira das lutas sociais, ora como limitação de oportunidades 
individuais, ora como protagonista das mazelas da comunidade.

Com efeito, as expectativas da sociedade civil relativamente à propriedade reclamam ao direito atuar visando condicioná-la econômica e socialmente, a fim "[...] de superar as violentas especulações a respeito de sua amplitude" (CASTRO, 2011).

Após a consolidação do Estado Democrático de Direito, a função social ocupou, junto com a dignidade da pessoa humana, entre outros princípios, o eixo central da proteção jurídica almejada e concedida pelo Estado(FACHIN, 2008, p. 212).

A repercussão desta corrente de pensamento alcançou institutos outrora consagrados no direito privado, implicando em sua impostergável releitura a partir de novos paradigmas, a exigir, inclusive, a ressignificação do poder de agir no tocante à autonomia privada.

É diante da evidente inoperância da ideia de propriedade frente às carências derivadas de uma estrutura social deficiente que alcança ainda maior relevância, no contexto deste debate, a situação possessória, a qual, de igual forma, deverá ser avaliada sob o crivo da função social.

A posse se impõe com maior flexibilidade e dinamismo, seja porque a propriedade é estática, seja porque a posse se realiza na conjuntura social. A funcionalização da posse se constata na demanda crescente da comunidade por mais espaços para moradia e trabalho. Assim, a posse qualificada se notabiliza pelo uso e apropriação de bens imóveis com vistas a atender necessidades individuais e coletivas.

Apregoar que a posse realiza direitos fundamentais significa reconhecer que a Constituição está sendo normativamente efetivada. A garantia da posse, ainda que relacionada à propriedade, por se tratar do núcleo do direito à moradia e ao trabalho, deve ser a todos assegurada, com igualdade e sem discriminação, abrangendo os indivíduos e as 
famílias, independentemente de cor, idade, gênero, condição econômica, grupo ou preferência política (OSÓRIO, 2004, p. 35).

Entretanto, no plano infraconstitucional acaba por estimular a conversão da posse qualificada em propriedade, por meio da usucapião, inclusive com a redução de prazos e a facilitação de procedimentos (como ocorre na usucapião extrajudicial), ao invés de conceder uma duradoura proteção jurídica à posse.

Constata-se, desta forma, que a tutela da situação jurídica possessória é provisória. Se assim for, em verdade, a usucapião possui duas principais facetas, diametralmente opostas.

A primeira, a demonstrar a força de uma situação possessória funcionalizada frente à propriedade ou a qualquer outro direito real (ALVIM, 2015, p. 2).

A segunda, indicando que para ser completamente protegida pelo ordenamento jurídico a posse deve tornar-se, afinal, propriedade, sendo a finalidade da usucapião "distribuir" a propriedade e não a afirmação da posse dentro da sistemática do direito civil. O objetivo final será sempre a sua transformação em direito real.

Independentemente da propriedade ou de qualquer outro direito real, a posse lastreada nos fundamentos antes expostos significa admitir a existência de direito subjetivo ao não-proprietário (TORRES, 2008, p. 354), que através da terra assegura um patrimônio mínimo capaz de lhe conceder uma existência autônoma.

\section{O POCEDIMENTO PARA ALÉM DA DESJUDICIALIZAÇÃO}

A Lei n. 13.105/2015 introduziu no ordenamento jurídico 
nacional o procedimento extrajudicial de usucapião, enquanto corolário da denominada desjudicialização, por sua vez decorrente do constante esforço no sentido de desafogar as serventias judiciais da exacerbada quantidade de demandas postas ao exercício da jurisdição, movimento que ganhou fôlego desde a Emenda Constitucional n. 45/2004, conhecida como "Reforma do Judiciário" (OLIVEIRA, 2011, p. 2-3).

Na prática, a previsão de variados procedimentos extrajudiciais precedeu a usucapião extrajudicial, valendo mencionar: a) a execução do contrato não cumprido de alienação fiduciária de bem imóvel; b) a retificação de registro de assentamento civil; c) a realização de inventário, partilha, separação consensual e divórcio consensual; d) a conversão em propriedade do título de legitimação de posse no âmbito do Programa Minha Casa, Minha vida.

$\mathrm{O}$ art. 1.071 do novo Código de Processo Civil acrescentou ao Capítulo III do Título V da Lei n. 6.015/1973 (Lei de Registros Públicos) o art. 216-A, in verbis:

Art. 216-A. Sem prejuízo da via jurisdicional, é admitido o pedido de reconhecimento extrajudicial de usucapião, que será processado diretamente perante o cartório do registro de imóveis da comarca em que estiver situado o imóvel usucapiendo, a requerimento do interessado, representado por advogado, instruído com:

I - ata notarial lavrada pelo tabelião, atestando o tempo de posse do requerente e seus antecessores, conforme o caso e suas circunstâncias;

II - planta e memorial descritivo assinado por profissional legalmente habilitado, com prova de anotação de responsabilidade técnica no respectivo conselho de fiscalização profissional, e pelos titulares de direitos reais e de outros direitos registrados ou 
averbados na matrícula do imóvel usucapiendo e na matrícula dos imóveis confinantes;

III - certidões negativas dos distribuidores da comarca da situação do imóvel e do domicílio do requerente; IV - justo título ou quaisquer outros documentos que demonstrem a origem, a continuidade, a natureza e o tempo da posse, tais como o pagamento dos impostos e das taxas que incidirem sobre o imóvel.

$\S 1^{\circ} \mathrm{O}$ pedido será autuado pelo registrador, prorrogando-se o prazo da prenotação até o acolhimento ou a rejeição do pedido.

$\S 2^{\circ}$ Se a planta não contiver a assinatura de qualquer um dos titulares de direitos reais e de outros direitos registrados ou averbados na matrícula do imóvel usucapiendo e na matrícula dos imóveis confinantes, esse será notificado pelo registrador competente, pessoalmente ou pelo correio com aviso de recebimento, para manifestar seu consentimento expresso em 15 (quinze) dias, interpretado o seu silêncio como discordância.

$\S 3^{\circ} \mathrm{O}$ oficial de registro de imóveis dará ciência à União, ao Estado, ao Distrito Federal e ao Município, pessoalmente, por intermédio do oficial de registro de títulos e documentos, ou pelo correio com aviso de recebimento, para que se manifestem, em 15 (quinze) dias, sobre o pedido.

§ 4응 o oficial de registro de imóveis promoverá a publicação de edital em jornal de grande circulação, onde houver, para a ciência de terceiros eventualmente interessados, que poderão se manifestar em 15 (quinze) dias.

$\S 5$ ํora a elucidação de qualquer ponto de dúvida, poderão ser solicitadas ou realizadas diligências pelo oficial de registro de imóveis.

$\S 6^{\circ}$ Transcorrido o prazo de que trata o $\S 4^{\circ}$ deste artigo, sem pendência de diligências na forma do $\S 5$ o deste artigo e achando-se em ordem a documentação, com inclusão da concordância expressa dos titulares 
de direitos reais e de outros direitos registrados ou averbados na matrícula do imóvel usucapiendo e na matrícula dos imóveis confinantes, o oficial de registro de imóveis registrará a aquisição do imóvel com as descrições apresentadas, sendo permitida a abertura de matrícula, se for o caso.

$\S 7^{\circ}$ Em qualquer caso, é lícito ao interessado suscitar o procedimento de dúvida, nos termos desta Lei. $\S 8^{\circ}$ Ao final das diligências, se a documentação não estiver em ordem, o oficial de registro de imóveis rejeitará o pedido.

§ 9ํㅡ A rejeição do pedido extrajudicial não impede o ajuizamento de ação de usucapião.

$\S 10$. Em caso de impugnação do pedido de reconhecimento extrajudicial de usucapião, apresentada por qualquer um dos titulares de direito reais e de outros direitos registrados ou averbados na matrícula do imóvel usucapiendo e na matrícula dos imóveis confinantes, por algum dos entes públicos ou por algum terceiro interessado, o oficial de registro de imóveis remeterá os autos ao juízo competente da comarca da situação do imóvel, cabendo ao requerente emendar a petição inicial para adequá-la ao procedimento comum (BRASIL, 1973).

A supressão da instância judicial demonstra evolução relativamente às disposições constantes do conjunto da normativa anterior em matéria de aquisição de bem imóvel por meio de usucapião. Isso porque, a recusa a uma exclusividade jurisdicional não suscita insegurança no processamento da usucapião, mormente em razão da fé pública registral em se tratando do procedimento extrajudicial.

Há que se afastar desde logo hipótese de arguição de violação ao artigo $5^{\circ}, \mathrm{XXXV}$, da Constituição Federal, uma vez que o caput do art. 216-A expressamente consignou que o pedido de reconhecimento 
extrajudicial de usucapião se dará sem prejuízo da via jurisdicional.

Percebe-se com a usucapião extrajudicial uma clara opção do legislador pelo atendimento da função social do imóvel urbano e rural, rompendo, ainda que timidamente, com a tradição dos códigos oitocentistas, como se depreende da lição de Arruda Alvim (2015, p. 1-3):

Dizia-se como verdade absoluta que no direito de usar do proprietário estava implicado o direito de não usar. É perceptível que essa afirmação se esgarçou, o que repercutiu na usucapião, pelas facilidades com que se pode usucapir. Ao longo dos anos, portanto, notouse certa flexibilização do valor absoluto do direito de propriedade, inclusive na doutrina. [...] O que se pode asseverar é que a evolução pela qual passaram o direito de propriedade e o impacto da consagração constitucional ampla da função social da propriedade veio a permitir a possibilidade de um instituto como a usucapião extrajudicial, que em outros tempos seria literalmente impensável. Some-se a isto o argumento normativo, de carga quase emocional, que decorre do texto constitucional de que todos devem ter direito à moradia (art. $6^{\circ}$, caput, da $\mathrm{CF} / 1988$, incluído pela EC 64/2010).

A argumentação até agora produzida leva a questionar a exigência do requisito constante do inciso II do art. 216-A, especificamente: " [...] planta e memorial descritivo assinado [...] pelos titulares de direitos reais e de outros direitos registrados ou averbados na matrícula do imóvel usucapiendo e na matrícula dos imóveis confinantes” (BRASIL, 1973).

Com idêntico entendimento, afirma Valestan da Costa (2015, p. 8) que:

[...] a exigência da anuência na planta do imóvel 
usucapiendo de todos os titulares de direitos reais e de outros direitos averbados ou registrados na matrícula conspira contra a usucapião extrajudicial, praticamente impossibilitando-a.

E por razões que parecem bastante óbvias. O próprio Costa $(2015$, p. 7), esclarece:

Pressupõe que todos os titulares de direitos reais e de outros direitos registrados ou averbados na matrícula do imóvel usucapiendo estejam vivos ou presentes e sejam conhecidos. Também pressupõe que o imóvel esteja matriculado e que a posse tenha sido exercida nos exatos termos da matrícula, o que também não condiz com a realidade dos casos de usucapião. Ledo engano. Muitos titulares de direitos na matrícula desaparecem. Muitos imóveis não estão matriculados.

Portanto, a hipótese normativa contida no inciso II do art. 216-A constata-se de todo inadequada. A usucapião é "[...] modo originário de aquisição da propriedade e outros direitos reais pela posse prolongada e qualificada por requisitos estabelecidos em lei” (PELUSO, 2010, p. 1.212). Como modo originário de aquisição não há que se falar em transferência de titularidade, não sendo de se exigir, sob nenhum fundamento, o consenso entre requerente e requerido.

Até porque, supõe-se que os interesses dos titulares de direitos reais e de outros direitos registrados ou averbados na matrícula do imóvel usucapiendo sejam diametralmente opostos aos do usucapiente. Ao atrair um caráter consensual para o seu reconhecimento, a usucapião extrajudicial foi praticamente reduzida a mera confirmação de negócios jurídicos pretéritos, com lastro ou não em justo título.

Destarte, cabíveis muitas indagações quanto à pretendida 
inovação procedimental:

[...] qual o interesse do usucapido em concordar? Se houvesse concordância, que necessidade haveria da usucapião? Se a aquiescência do titular do domínio é um requisito, qual o sentido da prescrição aquisitiva? O mesmo se pode dizer em relação aos demais titulares de direitos reais ou outros direitos registrados ou averbados na matrícula do imóvel "usucapiendo" (moradia, uso, usufruto, locação, hipoteca, anticrese, caução, garantia fiduciária, penhora) por ser a usucapião saneadora de todos os ônus ou gravames existentes no imóvel em razão da sua natureza de aquisição originária da propriedade (COSTA, 2015, p. 9).

Porquanto não seria demasiado concluir que o inciso II do art. 216-A acabou por inaugurar verdadeira modificação quanto à natureza jurídica da usucapião, alterando a própria essência deste consagrado instituto jurídico. Daí, na sequência da constatação acima exposta, poder afirmar-se que o legislador acabou por criar uma outra modalidade de regularização fundiária, de natureza privada e consensual.

Soma-se àquele descabido requisito a insólita determinação contida no $\S 2^{\circ}$ do art. 216-A, em destaque:

Se a planta não contiver a assinatura de qualquer um dos titulares de direitos reais e de outros direitos registrados ou averbados na matrícula do imóvel usucapiendo e na matrícula dos imóveis confinantes, esse será notificado pelo registrador competente, pessoalmente ou pelo correio com aviso de recebimento, para manifestar seu consentimento expresso em 15 (quinze) dias, interpretado o seu silêncio como discordância (BRASIL, 1973, grifouse). 
Caso não consiga superar a barreira imposta pelo inciso II do art. 216-A, o usucapiente dependerá do êxito das notificações expedidas pelo registrador - disposição expressa dos titulares de direitos reais e de outros direitos registrados ou averbados na matrícula do imóvel usucapiendo e na matrícula dos imóveis confinantes - para ver atendido o segundo requisito do seu pedido de usucapião extrajudicial.

Para dificultar ainda mais a sua aplicação, a parte final do $\S 2^{\circ}$ do art. 216-A preceitua que passados in albis quinze dias da notificação o silêncio dos titulares de direitos reais e de outros direitos registrados ou averbados na matrícula do imóvel usucapiendo e na matrícula dos imóveis confinantes será tomado como discordância.

Vislumbra-se, pois, destinada à insignificância jurídica a recémchegada usucapião extrajudicial, a menos que alterações substanciais sejam introduzidas no dispositivo legal em comento. As proposições que se entende adequadas foram apropriadamente sintetizadas por Valestan da Costa (2015, p. 11):

[...] considerar suficiente a assinatura na planta do requerente, de profissional habilitado, com prova de anotação de responsabilidade técnica no órgão competente, e dos confinantes, com firma reconhecida, desde que comprovada a notificação do titular do domínio pelos meios permitidos em lei, inclusive edital, e a ciência do poder público na forma já prevista no $\S 3 .^{\circ}$ do artigo em comento, presumindo-se o silêncio do titular do domínio como aceitação do requerimento da usucapião.

Um contraponto é sempre salutar, ainda mais quando proveniente de respeitado representante acadêmico: 
Vale ressaltar um ponto importante da regulamentação normativa: se o confinante ou titular de direitos reais não se manifestar, não se presume sua anuência. A solução adotada é oposta à vigente na retificação extrajudicial, em que o silêncio do confinante notificado implica concordância tácita (Lei de Registros Públicos, artigo 213, parágrafo $5^{\circ}$ ). Com a cautela legislativa, a segurança jurídica foi privilegiada em detrimento da efetividade. Um estudo estatístico que analise o número de retificações administrativas em comparação com o de contestações judiciais posteriores pode servir para confirmar a solução do novo artigo 216-A, ou para indicar a necessidade de sua reforma posterior (ALBUQUERQUE JÚNIOR, 2015, p. 3).

Com a devida reverência, tal pensamento somente poderia prosperar em um ambiente jurídico pautado no normativismo. Explica Castanheira Neves (1998, p. 37):

Pode dizer-se muito em geral que o normativismo é aquela perspectiva que compreende o direito como um autonomamente objectivo e sistemático 'conjunto de normas' - não como um complexo casuístico de decisões concretas, não como uma aberta e judicativodoutrinal jurisprudência normativamente constituída, não como uma determinável e estruturante instituição etc.

Um direito assim pensado remete seu sentido a referir-se " $[\ldots]$ a prévias normas jurídicas vinculantes que o jurista só haveria de conhecer e dedutivamente aplicar - tomadas de momento 'normas', 'prescrições', ‘regras' etc. como sinónimos" (NEVES, 1998, p. 37). Isso implica dizer que o ideal de segurança jurídica ali externado está identificado com 
certeza ou previsibilidade, atributos conferidos pela "imanente coerência" contida na racionalidade enquanto particular destaque da índole teórica do normativismo - sobretudo no sistemático normativismo horizontal, em que normas estão em conexão com outras normas no mesmo plano lógico (NEVES, 1998, p. 55-56).

A segurança, que não se pretende com esta argumentação refutar, é “[...] um importante efeito da ordem jurídica [...]”, como afirma Fernando Bronze (2010, p. 133). Mas apenas os descrentes a dariam hoje a centralidade do direito, como se lhe bastasse à sua realização. Pois que "[...] é certo ser esta uma segurança [...] insegura, porque o homem é indeterminado" (BRONZE, 2010, p. 132).

\section{CONCLUSÃO}

O propósito do legislador com a inovação produzida pelo art. 1.071 do Código de Processo de Civil, há pouco em vigor, que introduziu o art. 216-A na Lei de Registros Públicos, não obstante bem intencionada, precisará ser aclarada se deseja lograr efetividade.

Com efeito, seguindo uma das seguintes coordenadas:

1) Ou para confirmar a normatividade presente na formulação original do referido dispositivo (a) em seu inciso II, "planta e memorial descritivo assinado [...] pelos titulares de direitos reais e de outros direitos registrados ou averbados na matrícula do imóvel usucapiendo e na matrícula dos imóveis confinantes" e (b) em seu $\S 2^{\circ}$,

[...] se a planta não contiver a assinatura de qualquer um dos titulares de direitos reais e de outros direitos registrados ou averbados na matrícula do imóvel usucapiendo e na matrícula dos imóveis confinantes, esse será notificado pelo registrador 
competente, pessoalmente ou pelo correio com aviso de recebimento, para manifestar seu consentimento expresso em 15 (quinze) dias, interpretado o seu silêncio como discordância (BRASIL, 1973).

2) $\mathrm{Ou}$, o que genuinamente se espera com fulcro neste estudo conferindo maior abrangência e maior celeridade à usucapião extrajudicial, e também para torná-la menos gravosa, pois do contrário será sempre mais atrativa a via judicial, porquanto o procedimento há pouco inaugurado demonstra roteiro demasiado burocrático -, para relativizar a exigência contida na $2^{\mathrm{a}}$ parte do seu inciso II ("planta e memorial descritivo assinado [...] pelos titulares de direitos reais e de outros direitos registrados ou averbados na matrícula do imóvel usucapiendo e na matrícula dos imóveis confinantes") e interpretando como concordância o silêncio de que trata o seu $\S 2^{\circ}$.

Tais soluções, além de mais consentâneas com os “[...] valores de celeridade e eficiência que informaram a produção do novo Código [de Processo Civil] [...]" (OLGADO, 2015, p. 11), não colocariam em risco a estabilidade jurídica do procedimento, eis que a "[...] usucapião não está imune aos mecanismos judiciais de reconhecimento de sua invalidade quando presente algum dos defeitos do negócio jurídico" (OLGADO, 2015, p. 11).

Da forma como encontra-se positivado, sequer seria possível confirmar, do ponto de vista teórico, tratar-se de usucapião a modalidade em tela, além do que relegando-se sua efetividade estar-se-ia confinando à não operabilidade sua prática social.

Tais deturpações não encontram respaldo na hodierna doutrina jurídica da interpretação, da qual se espera bem mais que uma mera investigação semântica do texto normativo, mas atividade intelectual 
única e integral que culmina na realização do direito, “[...] reconhecendose que a interpretação jurídica é essencialmente a compreensão do critério normativo da concreta solução do problema" (AMARAL, 2003, p. 208).

\section{REFERENCIAS}

ALBUQUERQUE JÚNIOR, Roberto Paulino de. O usucapião extrajudicial no novo código de processo civil. Consultor Jurídico, São Paulo, 18 maio 2015. Disponível em: <http://www.conjur.com. br/2015-mai-18/direito-civil-atual-usucapiao-extrajudicial-codigoprocesso-civil>. Acesso em: 06 abr. 2016.

ALVIM, Arruda. A usucapião extrajudicial e o novo código de processo civil. Revista de Direito Imobiliário, São Paulo, v. 79, p. 15-31, jul./dez. 2015. Disponível em: < http://www.irib.org.br/app/ webroot/publicacoes/rdi79/pdf.pdf $>$. Acesso em: 09 abr. 2016.

AMARAL, Francisco. Direito civil: introdução. 5. ed. rev., atual. e aum. de acordo com o novo Código Civil. Rio de Janeiro: Renovar, 2003.

BECKER, Laércio Alexandre; SANTOS, Edson Luiz da Silva dos Santos. Elementos para uma teoria crítica do processo. Porto Alegre: Sergio Antônio Fabris, 2002.

BRASIL. Constituição (1988). Constituição da república federativa do brasil. Disponível em: <http://www.planalto.gov.br/ccivil_03/ Constituicao/Constituicao.htm>. Acesso em: 21 mar. 2017.

. Lei n. ${ }^{\circ} 6.015$, de 31 de dezembro de 1973. Disponível em: < http://www.planalto.gov.br/ccivil_03/leis/L6015compilada. htm>. Acesso em: 21 mar. 2017.

. Lei n. ${ }^{\circ} 10.406$, de 10 de janeiro de 2002. Código civil. 
Disponível em: <http://www.planalto.gov.br/ccivil_03/leis/2002/ 110406.htm>. Acesso em: 21 mar. 2017.

. Lei n. ${ }^{\circ} 13.105$, de 16 de março de 2015. Código de processo civil. Disponível em: < http://www.planalto.gov.br/ ccivil_03/_Ato2015-2018/2015/Lei/L13105.htm>. Acesso em: 18 mar. 2017.

BRONZE, Fernando José. Lições de introdução ao direito. 2. ed. Coimbra: Coimbra Editora, 2010.

CASTRO, Thainá Lima Bittencourt de. O direito à propriedade em face da função social: indivíduo x sociedade. Âmbito Jurídico, Rio Grande, v. 14, n. 94, nov. 2011. Disponível em: <http://www. ambitojuridico.com.br/site/index.php?n_link=revista_artig os leitura\&artigo_id=10766>. Acesso em: 30 abr. 2016.

COSTA, Valestan Milhomem da. Os requisitos para a usucapião extrajudicial na sistemática do novo código de processo civil e a questão da competência funcional do tabelião de notas e do oficial do registro de imóveis. Revista de Direito Imobiliário, São Paulo, v. 79, n. 38, p. 155-177, jul./dez. 2015. Disponível em: < http://www.irib. org.br/app/webroot/publicacoes/rdi79/pdf.pdf>. Acesso em: $30 \mathrm{abr}$. 2016.

FACHIN, Luiz Edson. O Direito que foi privado: a defesa do pacto civilizatório emancipador e dos ataques a bombordo e a boreste. Revista de Informação Legislativa, Brasília, v. 45, n. 179, p. 208217 jul./set. 2008.

\section{. A função social da posse e a propriedade}

contemporânea: uma perspectiva da usucapião imobiliária rural). Porto Alegre: Sergio Antônio Fabris, 1988. 
GAMA, Guilherme Calmon Nogueira da. Reconhecimento extrajudicial da usucapião e o novo código de processo civil. Revista de Processo, São Paulo, v. 259, p. 371-402, set. 2016.

GUSTIN, Miracy Barbosa de Sousa; DIAS, Maria Tereza Fonseca. (Re)pensando a pesquisa jurídica. 4. ed. Belo Horizonte: Del Rey, 2013.

MARQUESI, Roberto

Wagner. Direitos reais agrários e função social. Curitiba: Juruá, 2001.

NEVES, António Castanheira. Teoria do direito. Coimbra: Universidade de Coimbra, 1998.

OLGADO, José Lucas Rodrigues. O papel da ata notarial no procedimento extrajudicial de usucapião. Revista de Direito Imobiliário, São Paulo, v. 79, p. 125-154, jul./dez. 2015.

OLIVEIRA, Fernanda Loures de. Usucapião administrativa: uma alternativa possível. Revista de Direito Privado, São Paulo, v. 48, p. 129-160, out./dez. 2011.

OSÓRIO, Letícia Marques. Direito à moradia adequada na América Latina. In: ALFONSIN, Betânia; FERNANDES, Edésio (Org.). Direito à moradia e segurança da posse no estatuto da cidade: diretrizes, instrumentos e processos de gestão. Belo Horizonte: Fórum, 2004. p. 17-39.

PELUSO, Cezar. Código civil comentado. 4. ed. Barueri, SP: Manole, 2010.

TARTUCE, Flávio. O novo CPC e o direito civil: impactos, diálogos e interações. São Paulo: Método, 2015. 
TORRES, Marcos Alcino de Azevedo. A propriedade e a posse: um confronto em torno da função social. 2. ed. Rio de Janeiro: Lumen Juris, 2008.

Como citar: BARROSO, Lucas Abreu; PASSAMANI, Brígida Roldi. Usucapião extrajudicial: o procedimento para além da desjudicialização. Scientia Iuris, Londrina, v. 21, n. 1, p.189-211, mar. 2017. DOI: 10.5433/2178-8189.2017v21n1p199. ISSN: 2178-8189.

Recebido em: 16/06/2016

Aprovado em: 10/01/2017 